\title{
Proceeding
}

Supplementary Issue: Summer Conferences of Sports Science. First International Conference in Iraq on Sport for Peace, 4 April 2019. Baghdad Science Institute, Baghdad, Iraq.

\section{Exploring the nexus of green information technology capital, environmental corporate social responsibility, environmental performance and the business competitiveness of Thai sports industry firms}

\author{
CHAIRIT THONGRAWD ${ }^{1}$, WASSANA BOOTPO ${ }^{2}$, SUKUNYA THIPHA ${ }^{3}$, KITTISAK JERMSITTIPARSERT ${ }^{4,5}$ \\ ${ }^{1}$ College of Logistics and Supply Chain, Suan Sunandha Rajabhat University, Bangkok, Thailand \\ ${ }^{2}$ Education Faculty, Ramkhamheang University, Bangkok, Thailand \\ ${ }^{3}$ Graduate College of Management, Sripatum University, Bangkok, Thailand \\ ${ }^{4}$ Department for Management of Science and Technology Development, Ton Duc Thang University, Ho Chi Minh City, \\ Vietnam \\ ${ }^{5}$ Faculty of Social Sciences and Humanities, Ton Duc Thang University, Ho Chi Minh City, Vietnam
}

\begin{abstract}
The prime objective of the current study is exploring the nexus of green information technology capital, environmental corporate social responsibility, environmental performance and the business competitiveness of Thai sports industry firms. The final sample of the study comprises of 434 respondents. Moreover, the study explains the way in which the competitiveness of business and environmental performance is increased through green information technology capital and environmental corporate and social responsibility. The SEM-PLS is used to analyses the data. The previous research studies did not incorporate the environmental performance, green issues of enterprise management, and competitiveness of business with reference to green IT capital. Therefore, to increase the investment on green IT capital by environmental corporate and social responsibility has been provided in this study. This ultimately improves the competitiveness of business and environmental performance. Moreover, a research framework has been developed for the competitiveness of business and environmental performance and for defining their association with the green IT capital and ECSR. It is found that the investment in structural capital support the organization in meeting the demand of market and this makes them bias towards investment in the relational and structural capital. Keywords: Green information technology capital; Corporate responsibility; Environment; Sports; Thailand.

Cite this article as:

Thongrawd, C., Bootpo, W., Thipha, S., \& Jermsittiparsert, K. (2019). Exploring the nexus of green information technology capital, environmental corporate social responsibility, environmental performance and the business competitiveness of Thai sports industry firms. Journal of Human Sport and Exercise, 14(5proc), S2127-S2141. doi:https://doi.org/10.14198/ihse.2019.14.Proc5.33

Corresponding author. Department for Management of Science and Technology Development, Ton Duc Thang University, Ho Chi Minh City, Vietnam.

E-mail: kittisak.jermsittiparsert@tdtu.edu.vn

Supplementary Issue: Summer Conferences of Sports Science. First International Conference in Iraq on Sport for Peace, 4 April 2019. Baghdad Science Institute, Baghdad, Iraq.

JOURNAL OF HUMAN SPORT \& EXERCISE ISSN 1988-5202

(c) Faculty of Education. University of Alicante

doi:10.14198/jhse.2019.14.Proc5.33
\end{abstract}




\section{INTRODUCTION}

There has been increase in the awareness of environmental issues since 1960s. Organizations are becoming responsible in their manufacturing activities to comply with the international policies and treaties including the Framework Convention on Climate Change (1992), the Kyoto Protocol (2005), and Montreal Protocol (1987), and European Union environmental directives. The significance of environmental treaties is increasing and its norms. Therefore, the process of implementation of such treaties has become strict as it can create a significant influence on the business environment (Black, Ghobadian, \& Gallear, 2017; Chuang \& Huang, $2015 \mathrm{~b}$ ). According to the traditional aspect, the companies should comply with the relevant policies and regulations of environment. Moreover, the productivity is reduced when limited resources are invested in the equipment, which is non-productive antipollution along with low investment in productive material (Taheri \& Stevenson, 2017). It has been revealed by some researchers that there is no significant influence of environmental performance on the performance of business (Jermsittiparsert, Siriattakul, \& Sangperm, 2019; Jermsittiparsert, Siriattakul, \& Wattanapongphasuk, 2019; Jermsittiparsert, Sutduean, \& Sutduean, 2019; Somjai \& Jermsittiparsert, 2019). The modern view states the use of energy and generation of waste can be reduced through good environmental performance of corporation. This results in reducing the cost (Black et al., 2017). It has been shown by research that additional costs are generated by complying with the environmental regulations. It may lead to reduction of cost in some areas. The investment on energy, recycling, paper saving, cost recovery in long term, increased efficiency of logistics, and direct costs including technology treatment are included. It was found by Chuang, Huang, and Huang (2018) that ICTs can provide assistance in operations, which are sustainable and it can create positive or negative influence on the environment. In the first level, the direct influence is created by ICT on the use, production, disposal, and recycling. In the second level, the indirect influence of ICT is created on the environment such the process of transportation. In the third level, the system influence is created, which refers to the change in the behaviour of user or changes in production patterns, economic structures, which result in change of consumption patterns (Chuang et al., 2018). It is believed by several researchers that IT creates an impact on the competitiveness of business along with reduction in cost and differentiation. Moreover, it can enhance the market competition. In this way, a crucial role is played by IT in sustaining competitive edge (Basheer, Siam, Awn, \& Hassan, 2019; Jones, 2016; Yagi, 2015). The reduction of the initial period results in the achievement of benefits through use of IT. The cost of electricity reduces along with the use of paper. This supports the organizations in attaining more benefits and reduction of cost. Similarly, green IT is not just elated to the reduction of cost, but it includes the complying with CSR and improving the value of brand. It has been believed by Brooks, Hedman, and Wang (2018) that greater energy efficiency can be delivered through use of IT systems such as making the computers switch to power saving mode or using virtualized server. This can create a significant influence on the enterprise structure. A competitive advantage is developed by the enterprise through use of IT systems. It has been claimed by Dangelico and Pontrandolfo (2015) that the volume of emissions can be reduced through green IT and energy can be saved. The alignment of strategic framework and green IT policy can result in green IT integration and with strategies of enterprise. It was believed by Higón, Gholami, and Shirazi (2017) that with the implementation of green TI, the use of technology, influence of environmental factors and organizational characteristics should be considered. Moreover, investment benefits can be acquired by an organizational consensus. Further, the process of green capital investment of IT is continuous, and it can improve the competitiveness of business and improve the value of brand by ensuring the business sustainability. Therefore, it is crucial to create a focus on the impact of business competitiveness created by green activities (Chuang \& Huang, 2015b). Several previous research studies have focus on the way in which the strict environmental policies are responded by business and the way in which stakeholders come across issues related to environment. The stakeholders may include the consumers, law enforcers, executives of corporate, residents of community 
and green consumers (Chuang \& Huang, 2015a). It is believed by Chuang and Huang (2018) that the sports sector can create a significant influence on the natural environment while manufacturing. The international regulations pertaining to environment have become strict. These have become a key to reduce the environmental influence. Over the recent years, issues related to ESCR have gained increased significance by the scholars along with the concept of green management (Grewatsch \& Kleindienst, 2017). Similarly, it is believed by Grewatsch and Kleindienst (2017) that the competitiveness of business can be achieved by ECSR. The competitiveness can be sustained for longer, when ECSR is managed and financed in an effective way. The relation between the variables has not been explained by the previous research studies. Moreover, some researchers have determined the association between competitiveness of business and environmental performance (Chuang \& Huang, 2015a) but there is need for a precise study. Based on this gap in literature, this research has identified the association between four variables through development of an empirical framework. Moreover, the study explains the way in which the competitiveness of business and environmental performance is increased through green IT and ECSR. The role of green capital IT has been analysed $a$. Three research gaps identified have been covered by this research. The results of Chuang and Huang (2015a) refer to the first gap. According to him, there is a significant positive influence of environmental performance on the competiveness of business. There is need for conducting a research to know whether the competitiveness of business is influenced through the environmental performance or vice versa. It was believed that ESCR is a crucial issue for activities of business, which refers to the second gap from the aspect of sustainable development of enterprise. Grewatsch and Kleindienst (2017) constructed the scale for ESCR and the number of variables should be increased by future research, which has high association with ECSR. Chuang and Huang (2015b) developed the concept of green IT capital, which is the third gap. It has been found by this research that a strong and positive influence is created on green IT capital by corporate greening. It is also recommended that the research variables, which can accumulate green IT capital, should be identified. For instance, the competitiveness of organizations can be increased through environmental management or corporate greening.

\section{HYPOTHESIS DEVELOPMENT}

The quality of life improves for the employees along with economic developed through the compliance of organizations with CSR. The focus of CSR is on responsibilities for internal and external stakeholders including board members, employees, managers, consumers, supply chain partners, communities and other groups (Groening \& Zhu, 2019). Higher investment is made in green initiatives including management innovation and green technology by giving significance to the green consumers. Moreover, when the corporate greening level is high, more investment is made by the companies in green human IT capita, green relational IT capita, green structural IT capital, etc (Chuang \& Huang, 2015b). Precisely, the corporate image is improving through ESCR by becoming conscious to the environment. The interest of stakeholders is analysed to assess the management and corporate governance. The fast execution of the action plans and strategies is involved in ESCR such as innovative products and training for sustainable performance of business. The stakeholders' demands are not just satisfied by green IT capital about the environmental concerns, but it also becomes a source of competitive advantage. Further, the capabilities and resources required for sustainable operations of business are provided by green IT capital. Resultantly, long-term investments are made by the businesses in green IT capital, which focus on ESCR. Based on the discussion, the following research hypothesis has been developed:

H1: ENCSR has significant impact on the GITCAP

The outcomes of environmental management and protection policy are measured through environmental performance. A definition has been established for the environmental performance by the International 
Organization for Standardization (ISO) in the ISO 14001:2004 (2004) standard. Measurable outcomes of the environmental management can be achieved through controlling the factors of environment by certain targets, environmental policy, and indicators. Moreover, it was believed by Kay and Alder (2017) that several companies have started giving focus to the assessment criteria of environmental performance development by the Coalition for Environmental Responsible Economics in the US. It was believed by Qiu, Shaukat, and Tharyan (2016) from the perspective of business investment that the future costs of environment are reduced through good environmental performance. The use of IT has become an intangible value for the firm considering the perspective of the business' intellectual capital. Certain tangible as well as intangible benefits are achieved by the organization through IT (Mao, Zhang, \& Deng, 2016). The use of environmental security in IT is referred as IT capital, which includes a series of green strategies for management including capital investment of green IT for manufacturing of equipment (software and hardware), IT systems, which are based on green concepts. Moreover, employees develop green capabilities of IT through green IT capital and this enables a coordination level with the partners in protecting environment. The needs of society concerning the protection of environment are met by creating intrinsic brand value and competitiveness of market (Chuang \& Huang, 2015b). The cooperative relations with the customers, partners, and residents of community concerned with the protection of environment can be improved through making investment in the green capital of IT. Therefore, it can also improve the business repute and image. The cost of environment can be reduced through green IT capital, the professional knowledge of employee improves along with technologies, which are energy saving. In the same way, the expectations of environmental regulations of government and norms can be understood by the businesses. Precisely, the organization can achieve higher environmental performance, when it enhances the strategies concerned with the green management (Chuang \& Huang, 2015a). The environmental performance of businesses can be improved through increase in investment on green IT capital. There is increased focus on gaining competitive advantage and competitiveness of business in the management filed. The competitiveness of business is referred as the use of strategies, which are difficult to be imitated by the competitors. In this way, the business sustains a good profitability margin (Jones, 2016; Nguyen \& Nguyen, 2018). A perspective has been taken from the RBV, which suggests that when the IT investment is complemented with the resources of organization, it enhances the processes and organizational performance through creation of business value. Several organizations implement IT to support the relation management with the customers, procurement processes, activities of supply chain and manufacturing (Nan \& Tanriverdi, 2017). All these aspects are in line with the RBV theory, which refers IT as a crucial factor for gaining competitive advantage (Kim \& Lu, 2019). The use of IT capabilities and resources create business value. Several researchers have revealed that the use of IT results in differentiation, reduction of cost and improvement in the competitiveness along with increasing the market competition. Moreover, business values and capabilities are created through IT. It plays a significant role in sustaining competitive edge (Jones, 2016; Yagi, 2015). It has been stated by Higón et al. (2017) in terms of business investment that investment in green IT results in two main advantages, which include the reduction of costs of IT and support for implementation of management strategies. Further, there are four main areas of green IT, in which enterprise can be management. These include environmental law, CSR, recycling of waste and cost saving. It was believed by Nesselroade and Grimm (2019) that the environmental issues can be resolved with the help of green IT along with exploring market opportunities. The environmental issues can be resolved by businesses through manufacturing of products complying with the vision and technology to reduce cost of energy and achieve competitive edge. It has been pointed out by Radu (2017) that there are ecological and economic benefits linked with green IT. The previous research studies have shown that investment in green IT results in cost saving, efficiency and competitiveness. It was believed that a positive influence is created on the competitiveness of business on green IT, green designing of product, recycling of waste, and green management. Moreover, the influence of green IT capital was analysed by Chuang and Huang (2015b) on the competitiveness of business competitiveness among the manufacturing companies in 
Taiwan. The results of the research revealed that the three dimensions of green IT capital including green relational IT capital, green structural IT capital, green human IT capital create a significant impact on the competitiveness of business. Concluding, green IT capital can be created by the businesses, when they are able to incorporate green aspects in the IT capital accumulation. This can enhance the competitiveness of business and environmental management of the corporation. The market competitiveness of the businesses is high, which make more investment in green human IT capital, green structural IT capital, green relational IT capital. Based on these discussions, the following research hypothesis has been developed:

H2: GITCAP has significant impact on the BCOMP

When spontaneous actions are taken by business related to the issues of environment, potential benefits can be obtained from the aspect of business strategy and environmental performance. This includes increased image of the corporation, consumer attraction concerned with the environment, positive reviews of investment, savings, conservation of energy, and improved relations with the communities and development of green products with high value (Chuang \& Huang, 2018). It has been believed by some researchers that stakeholders' satisfaction increases through sustained action of the businesses, which ultimately improves the business competitiveness. It was believed by Black et al. (2017) that pollution should be regarded by businesses as a wasteful activity. Companies have high market competitiveness, which are leaders in the investment made for the protection of environment. The environmental performance is accessed on different levels which are operational, tactical, and strategic (see figure 1)

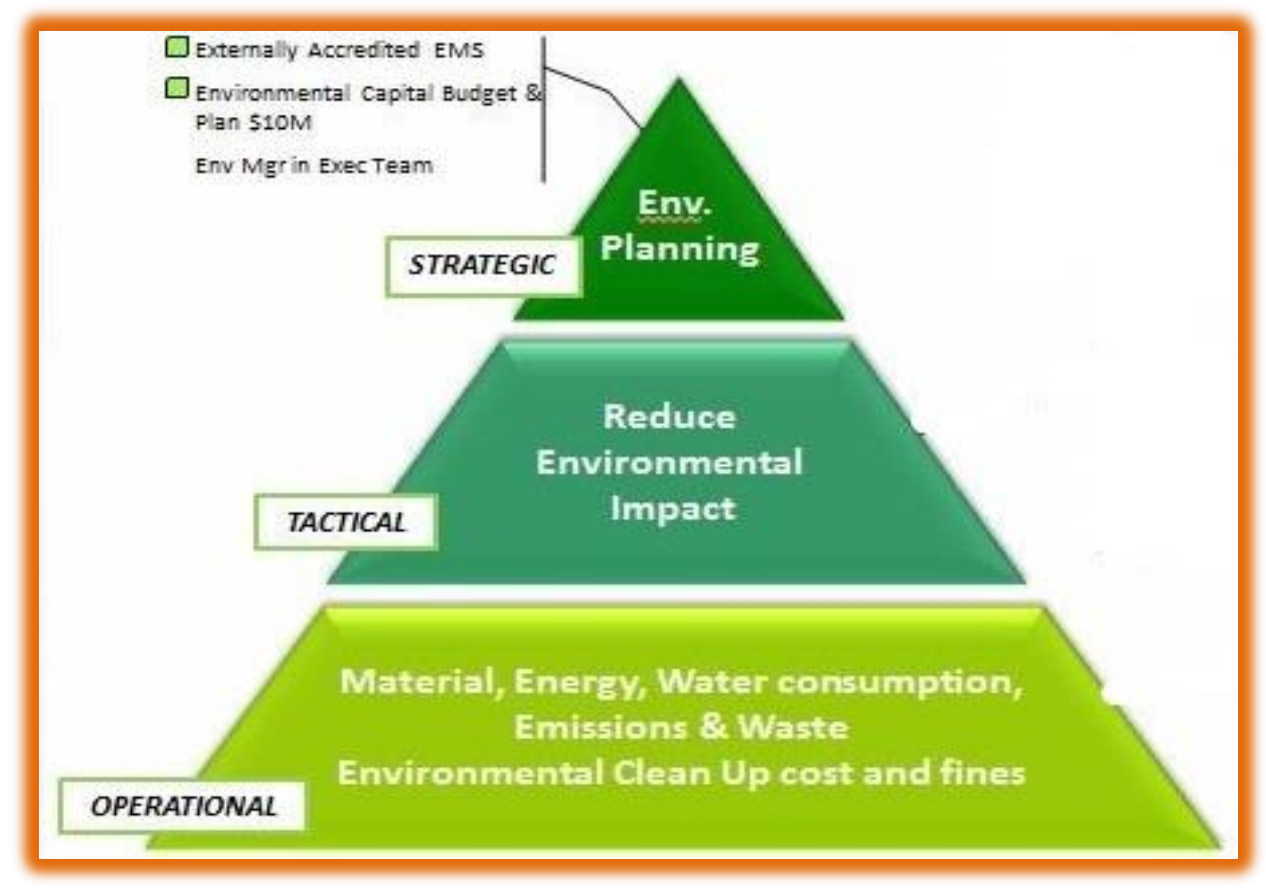

Figure 1. Environment performance review model.

This reflects that they can charge high price for the products because of high corporate value and use of green technologies in the production processes. This established new market opportunities for them and result in the achievement of competitive advantage. Meanwhile, the corporate departments' function and environmental goals are combined in the environmental management strategies by the businesses. The fines and protests related to environmental issues can be avoided by using environmental technology, which is 
innovation. This improves the image of corporate and explores new opportunities in the market along with improving the competitiveness of business (Chuang \& Huang, 2015a; Epstein, 2018). A firm with high market competitiveness can charge high product price because of the use of green and environmentally safe technologies, high corporate image and valued services. For this, they can achieve and sustain competitive advantage as well.

H3: ENVP has significant impact on the BCOMP

Based on the above discussions, it can be said that social benefits can be achieved when a firm invest in green technology and energy saving activities to comply with its CSR policy. The expertise relative to every industry is used effectively by the government. According to Hedman and Henningsson (2016), the intangible advantages of IT have greater significance as compared with the tangible ones. Different organizational resources are combined with IT, which developed new capabilities and offer a source for achieving competitive advantage. For combining IT and environmental goals in a proactive strategy for environmental management, more investments can be made by the businesses in green IT capital to manufacture products, which are green and demand by the consumers (Chuang \& Huang, 2015b). In this way, the organizations can cope with the environmental challenges and deal with the requirements of consumers. Moreover, when more activities are organized by businesses for protection of environment including green IT, high market competitiveness can be achieved (Nguyen \& Nguyen, 2018). When a proactive strategy is adopted for environmental management, this can result in higher environmental performance (Chuang \& Huang, 2015a). A greater investment is required to be made in green IT capital for complying with the CSR to protect environment. This strengthens the environmental technology, which is innovative for resolving the issues related to environment. Further, the innovation capabilities improve with more investments made in green IT capital. This enables the organization to develop a unique capability for gaining competitive advantage along with improving the environmental performance. This research study suggests that there can be a significant influence of IT capital on the relation of environmental performance and ECSR and the relation of business competitiveness and ECSR. Investment is required to be made in the green structural capital of IT, green human IT capita, green relational IT capital for improve the competitiveness of business and environmental performance. Based on this, the following research hypotheses can be formulated:

H4: GITCAP has significant impact on the BCOMP

\section{METHODOLOGY AND MEASUREMENT}

This research has used inferential and descriptive statistics for collection of data. For screening of data, profile of respondents and data analysis for first research question was done through use of SPSS22. The study measured the job satisfaction level of lecturers. The five-group classification was made for the sevenpoint scale. The mean value was classified into five groups such as very low, low, moderate, high, and very high representing the values 1.00-2.20, 2.21-3.40, 3.41-4.60, 4.61-5.80, and 5.81-7.00 respectively (Korkut Altuna \& ARSLAN, 2016). The Smart PLS 3.1.2 was used to assess the reliability and validity of the research instruments for second and third hypotheses. The structural model and measurement model were determined. This analysis is regarded as the multivariate data analysis of the second generation. There were more than 40 items included in one out of 434 questionnaires, which were received. This was higher than the $10 \%$, which was not responded. According to Hair, Sarstedt, Hopkins, and Kuppelwieser (2014), these cannot be used for data analysis because of missed responses and removed from the sample. The use of PLS-3 software enables the researcher to detect whether there is any missing value or data. This characteristic of the PLS-3 was enable and it found that all the respondents have respondent all the items. 


\section{Measures}

A 12 scale item has been used to measure ECSR taken from Grewatsch and Kleindienst (2017) to measure ECSR $(a=0.94)$. The scale for green IT capital has been adopted from Chuang and Huang $(2015 b)$. The environmental performance was measured based on a 10 -item scale proposed. Eight items related to environmental performance were included in the questionnaire $(a=0.96)$. The business competitiveness was measured by using a 10 item scale $(a=0.94)$ given by Nguyen and Nguyen $(2018)$.

\section{Data analysis}

The variation of correlation and multiple regression analysis is referred as Smart PLS-3. The loading coefficient and path estimates can be measured through it. The AVE value is estimated and used in PLS-3. The data set is bootstrapped using AVE value. Moreover, it is used for data analysis in case the model is complicated and of higher order. Four constructs have been used in this study that of second order (Nejati, Mohamed, \& Omar, 2015). The elements used in this research are formative and almost 75 elements are reflective. Therefore, the use of any other software may not give the appropriate results using this type of data (Hair, Hult, Ringle, \& Thiele, 2017). The nature of this research makes it effective to adopt PLS 3 because it involves use of measurement error. Information is sourced through use of PLS-3 approach about the association of the variables. The variable relations were analysed for the model, which is referred as determination of structural model. The estimates of variables were determined through use of Smart PLS and the relations were verified and predicted. In this research, the importance-performance matrix was shown by use of PLS.

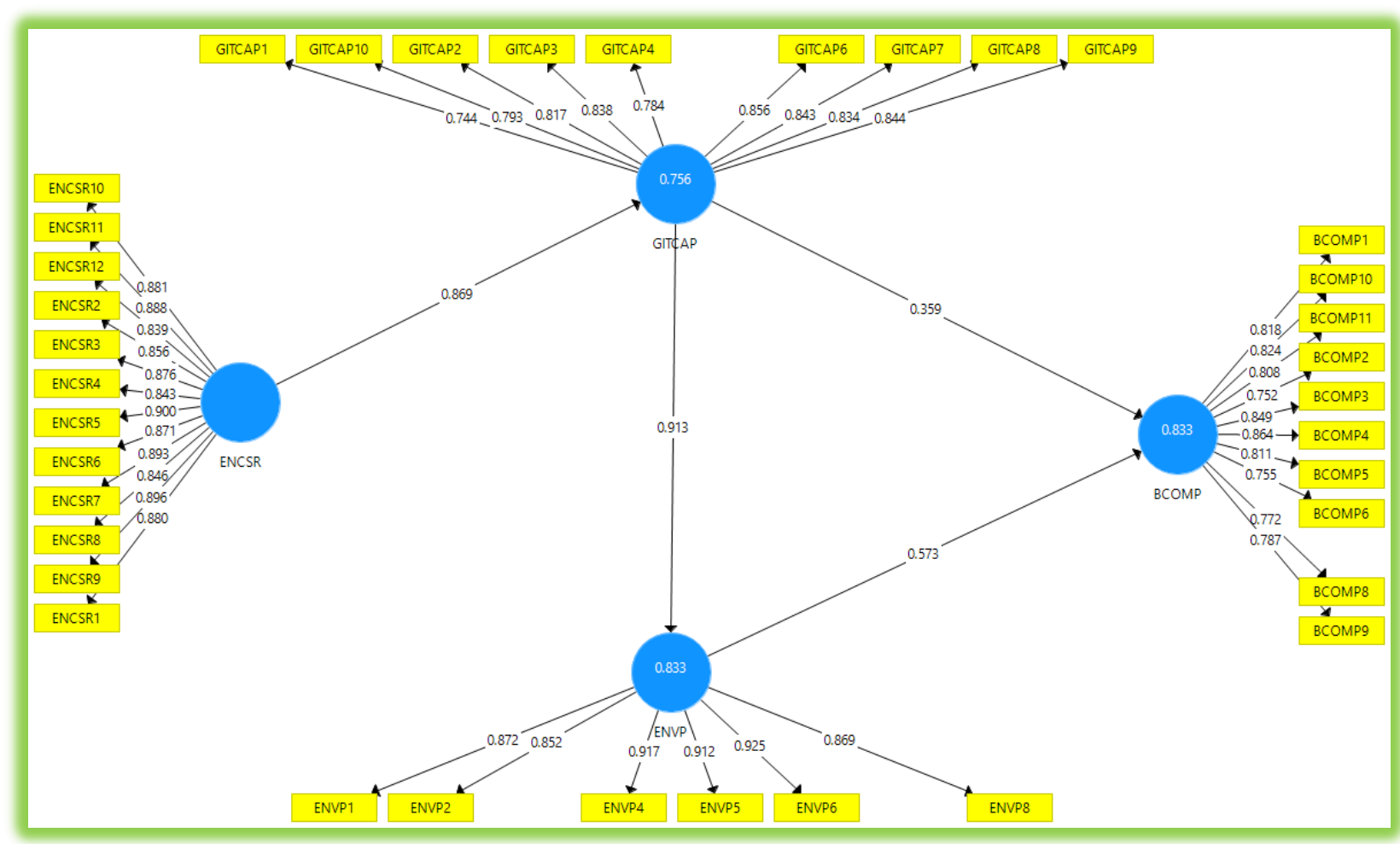

Figure 2. Measurement Model. 
Table 1. Outer Loadings.

\begin{tabular}{|c|c|c|c|c|}
\hline & BCOMP & ENCSR & ENVP & GITCAP \\
\hline BCOMP1 & 0.818 & & & \\
\hline BCOMP10 & 0.824 & & & \\
\hline BCOMP11 & 0.808 & & & \\
\hline BCOMP2 & 0.752 & & & \\
\hline BCOMP3 & 0.849 & & & \\
\hline BCOMP4 & 0.864 & & & \\
\hline BCOMP5 & 0.811 & & & \\
\hline BCOMP6 & 0.755 & & & \\
\hline BCOMP8 & 0.772 & & & \\
\hline BCOMP9 & 0.787 & & & \\
\hline ENCSR10 & & 0.881 & & \\
\hline ENCSR11 & & 0.888 & & \\
\hline ENCSR12 & & 0.839 & & \\
\hline ENCSR2 & & 0.856 & & \\
\hline ENCSR3 & & 0.876 & & \\
\hline ENCSR4 & & 0.843 & & \\
\hline ENCSR5 & & 0.900 & & \\
\hline ENCSR6 & & 0.871 & & \\
\hline ENCSR7 & & 0.893 & & \\
\hline ENCSR8 & & 0.846 & & \\
\hline ENCSR9 & & 0.896 & & \\
\hline ENVP1 & & & 0.872 & \\
\hline ENVP2 & & & 0.852 & \\
\hline ENVP4 & & & 0.917 & \\
\hline ENVP5 & & & 0.912 & \\
\hline ENVP6 & & & 0.925 & \\
\hline ENVP8 & & & 0.869 & \\
\hline GITCAP1 & & & & 0.744 \\
\hline GITCAP10 & & & & 0.793 \\
\hline GITCAP2 & & & & 0.817 \\
\hline GITCAP3 & & & & 0.838 \\
\hline GITCAP4 & & & & 0.784 \\
\hline GITCAP6 & & & & 0.856 \\
\hline GITCAP7 & & & & 0.843 \\
\hline GITCAP8 & & & & 0.834 \\
\hline GITCAP9 & & & & 0.844 \\
\hline ENCSR1 & & 0.880 & & \\
\hline
\end{tabular}

It has been recommended by Hair et al. (2014) that the relation between the observed and unobserved variable is reflected through measurement model. CFA analysis is conducted to determine the measurement model. This involves the use of convergent, discriminate validity as well as items' reliability. The values for $\mathrm{CR}$ (composite reliability) and AVE (average variance extracted) were determined. As per the rule set by (Tang \& Chaw, 2016), the value of CR should lie above 0.7 and AVE above 0.5 for acceptance. According 
to Lonial and Carter (2015), the value of Cronbach alpha should be greater than 0.7 . When the value of outer loadings of model is higher than the value 1.95 at significance level of 0.05 , the convergent validity is determined. After the researcher determines the measurement model and assures the reliability and validity, the next step involves the determination of structural model. The VIF value was analysed for test of multicollinearity, along with the index condition and value of tolerance for the explanatory variables. The amount of variation in the independent variable, which is not explained by the other explanatory variables in the structural model, is referred as tolerance. However, VIF refers to the level with which the issue of collinearity inflates the standard error.

Table 2. Reliability.

\begin{tabular}{|l|c|c|c|c|}
\hline & Cronbach's Alpha & rho_A & Composite Reliability & Average Variance Extracted (AVE) \\
\hline BCOMP & 0.940 & 0.945 & 0.948 & 0.647 \\
\hline ENCSR & 0.971 & 0.972 & 0.975 & 0.762 \\
\hline ENVP & 0.948 & 0.950 & 0.959 & 0.795 \\
\hline GITCAP & 0.938 & 0.939 & 0.948 & 0.669 \\
\hline
\end{tabular}

Table 3. Validity.

\begin{tabular}{|l|l|l|l|l|}
\hline & BCOMP & ENCSR & ENVP & GITCAP \\
\hline BCOMP & 0.805 & & & \\
\hline ENCSR & 0.734 & 0.873 & & \\
\hline ENVP & 0.801 & 0.714 & 0.892 & \\
\hline GITCAP & 0.782 & 0.869 & 0.813 & 0.818 \\
\hline
\end{tabular}

$\mathrm{Cl}$ (condition index) refers to assessment whether there is critical collinearity in the measurement models, which are formative (Henseler, Ringle, \& Sarstedt, 2015). When the value of tolerance is equal or lower than 0.2 , the value of VIF is equal or greater than 5.0 , and condition index is 30 , this refers to the problem of multicollinearity. Results reflect these values, where all the values of VIE are lower than 6 and the value of tolerance greater than 0.20 . The value of condition index is lower than 30 . This means, there is no issue of multicollinearity in this research.

The relation of dependent variable with constructs in the model is involved in the assessment of structural model (Hair et al., 2014). The interrelations between the constructs are represented in the structural model. It defines the association between the unobserved variables. In this research, the relations hypothesized were tested in the structural model assessment, which comprised of explanatory variables including behaviour, leadership styles, decision making. The dependent variable is job satisfaction. The issues of collinearity, significance, and relevance were determined in the structural model. Standard errors and t-values were determined through bootstrapping, which show the non-parametric approach for precision estimation of estimates of PLS. The researcher was allowed to determine the significance of path coefficient statistically.

Table 4. Direct Relation.

\begin{tabular}{|l|l|l|l|l|l|}
\hline & $(\mathbf{O})$ & $(\mathbf{M})$ & (STDEV) & $($ |O/STDEV $\mid)$ & P Values \\
\hline ENCSR -> GITCAP & 0.869 & 0.869 & 0.030 & 29.231 & 0.000 \\
\hline ENVP -> BCOMP & 0.573 & 0.573 & 0.084 & 6.855 & 0.000 \\
\hline GITCAP -> BCOMP & 0.359 & 0.360 & 0.087 & 4.117 & 0.000 \\
\hline GITCAP -> ENVP & 0.913 & 0.913 & 0.015 & 62.591 & 0.000 \\
\hline
\end{tabular}




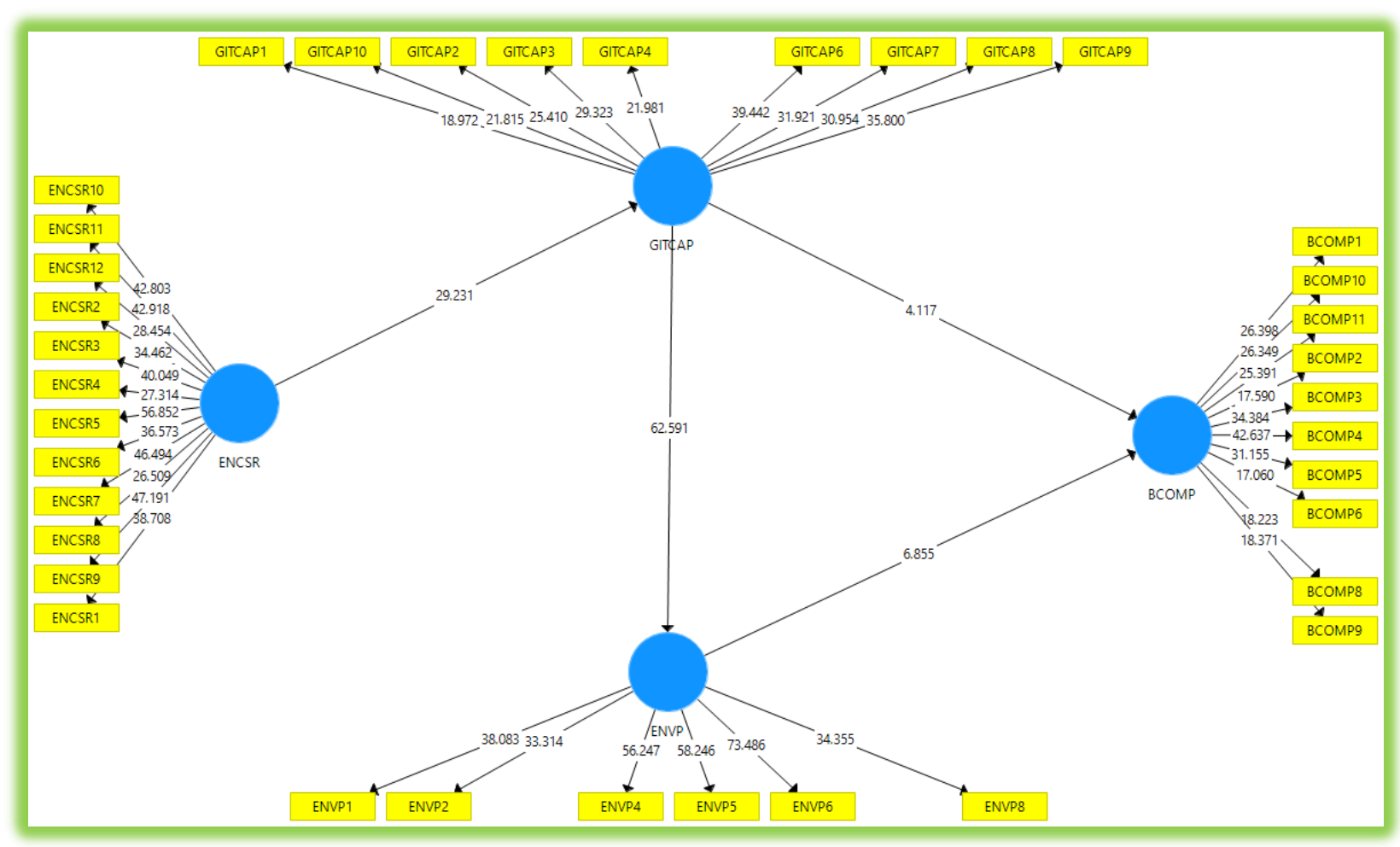

Figure 3. Structural Model.

$\mathrm{R} 2$ is the coefficient of determination, which is the ability of independent variables to explain or predict the dependent variable in the research model. It is also referred as goodness of fit and its value is usually ranging from 0 to 1 . The higher the value of R2 the higher is the explanatory or predictive power of explanatory variables (Hair et al., 2014).

Table 5. R-square.

\begin{tabular}{|l|l|}
\hline & R Square \\
\hline BCOMP & 0.833 \\
\hline ENVP & 0.833 \\
\hline GITCAP & 0.756 \\
\hline
\end{tabular}

The relative predictive relevance of an explanatory construct on the dependent construct is determined by the measure of predictive relevance. The reflective construct's relevance is assessed through SEM model (structural equation modelling). The process of blindfolding was adopted to calculate Q2. The predictive relevance of the variables was used to determine the approach of cross-validated redundancy. It was suggested by Hair et al. (2014) that the structural model elements, and eliminated predicted data and path model are included in the assessment of the approach of cross-validated redundancy. 


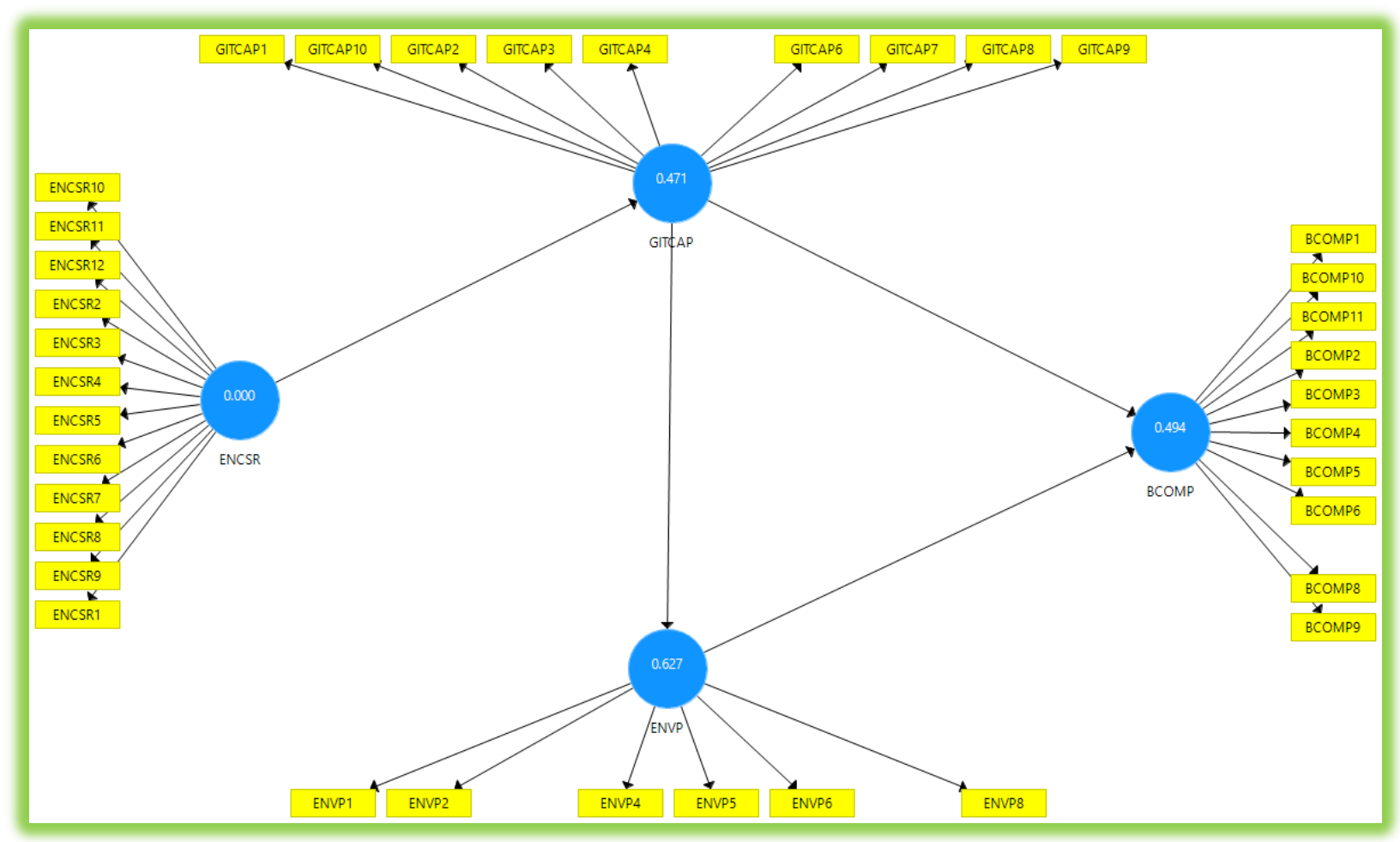

Figure 4. Q-square.

Table 6. Q-square.

\begin{tabular}{|l|l|l|l|}
\hline & SSO & SSE & $\mathbf{Q}^{2}(=1-$ SSE/SSO $)$ \\
\hline BCOMP & $2,170.000$ & $1,097.122$ & 0.494 \\
\hline ENCSR & $2,604.000$ & $2,604.000$ & \\
\hline ENVP & $1,302.000$ & 485.992 & 0.627 \\
\hline GITCAP & $1,953.000$ & $1,033.796$ & 0.471 \\
\hline
\end{tabular}

The previous research studies did not incorporate the environmental performance, green issues of enterprise management, and competitiveness of business with reference to green IT capital. Therefore, to increase the investment on green IT capital by ESCR has been provided in this study. This ultimately improves the competitiveness of business and environmental performance. Moreover, a research framework has been developed for the competitiveness of business and environmental performance and for defining their association with the green IT capital and ECSR. It has been revealed through empirical results that there is significant positive association of ECSR with green IT capital including green structural IT capital, green human IT capita, green relational IT capital. It shows that there is need for more investment in all the three dimensions of green IT capital when ECSR is high. It was pointed by Vracheva, Judge, and Madden (2016) that business concerned with environmental issues invest in activities related to green management. Moreover, it has been found by this research study that there is a significant influence of green relation IT capital and green structural IT capital on the business competitiveness and environmental performance. There is not significant influence of green human IT capital on the business competitiveness and environmental performance. It has been contended by Chuang and Huang (2018) that businesses can adapt to the change in environment through making investment in green relational IT capital and green structural IT capital. Moreover, the internal organizational procedures are linked with the attributes of the structural 
capital. It has been demonstrated by Chuang and Huang (2018) that the sports sector of Thailand has given more focus to the investment in green relational capital. This shows the concern of sports sector with the establishment of green relations with suppliers, strategic partners, customers, etc. to benefit everyone. Investment in green relational IT capital and green structural IT capital has resulted in an increase in competitiveness of business and environmental performance.

\section{CONCLUSION}

The sports sector of Thailand plays a significant role in development process of the economy. In this regard, its contribution to the economic development cannot be neglected. With the increase in concerns for environmental protection and CSR, businesses have started developing new policies as part of CSR. Moreover, they expect collaborative efforts from the employees. It has been found by the research that investments are made in green structural IT capita, green relational IT capital by the firms who are concerned for ECSR. These firms enjoy improved performance in terms of competitiveness and environmental initiatives. The management implications have been elaborated by this research for ECSR, green relational IT capital and green structural IT capital. The corporate commitments and philosophy should incorporate the environmental thinking for improve the CSR image. Businesses should offer products, which comply with the regulations of environment and add to sustainable development. The environmental measures adding to the business outcomes should be considered by the managers along with the cost and time. Employees are supported to through shared beliefs and values to understand the way in which organizations carry out their activities. This supports in having a high sense of recognition with the environmental policies of organization and pro-environmental behaviour and attitude development among the employees at corporate and individual level. When the competitive strategy of a company includes ECSR as an integral part in the sports sector, the focus of the companies should be on attaining sustainable benefits from these issues. Other than making investment in tangible assets including green IT equipment, the sports sector of Thailand should focus on the development of collaborative relations with the customers and other firms to support green thinking (Nguyen \& Nguyen, 2018). Moreover, investment in structural capital support the organization in meeting the demand of market and this makes them bias towards investment in the relational and structural capital (Lu \& Hsu, 2018).

\section{REFERENCES}

Basheer, M., Siam, M., Awn, A., \& Hassan, S. (2019). Exploring the role of TQM and supply chain practices for firm supply performance in the presence of information technology capabilities and supply chain technology adoption: A case of textile firms in Pakistan. Uncertain Supply Chain Management, 7(2), 275-288. https://doi.org/10.5267/j.uscm.2018.9.001

Black, A., Ghobadian, A., \& Gallear, D. (2017). Environmental regulations, innovation and firm performance: A revisit of the Porter hypothesis. Journal of Cleaner Production, 155, 79-92. https://doi.org/10.1016/i.jclepro.2016.08.116

Brooks, S., Hedman, J., Sarker, Saonee, \& Wang, X. (2018). Antecedents and Effects of Green IS Adoptions: Insights from Nordea. Journal of Cases on Information Technology (JCIT), 20(4), 32-52. https://doi.org/10.4018/jcit.2018100103

Chuang, \& Huang. (2015a). Effects of business greening and green IT capital on business competitiveness. Journal of Business Ethics, 128(1), 221-231. https://doi.org/10.1007/s10551-014$\underline{2094-y}$ 
Chuang, \& Huang. (2015b). Livestock-associated meticillin-resistant Staphylococcus aureus in Asia: an emerging issue? International journal of antimicrobial agents, 45(4), 334-340. https://doi.org/10.1016/j.jiantimicag.2014.12.007

Chuang, \& Huang. (2018). The effect of environmental corporate social responsibility on environmental performance and business competitiveness: The mediation of green information technology capital. Journal of Business Ethics, 150(4), 991-1009. https://doi.org/10.1007/s10551-016-3167-x

Chuang, Huang, S.-J., \& Huang, S.-J. (2018). The effect of environmental corporate social responsibility on environmental performance and business competitiveness: The mediation of green information technology capital. Journal of Business Ethics, 150(4), 991-1009. https://doi.org/10.1007/s10551016-3167-x

Dangelico, R. M., \& Pontrandolfo, P. (2015). Being 'green and competitive': the impact of environmental actions and collaborations on firm performance. Business Strategy and the Environment, 24(6), 413430. https://doi.org/10.1002/bse.1828

Epstein, M. J. (2018). Making sustainability work: Best practices in managing and measuring corporate social, environmental and economic impacts: Routledge. https://doi.org/10.4324/9781351280129-3

Grewatsch, S., \& Kleindienst, I. (2017). When does it pay to be good? Moderators and mediators in the corporate sustainability-corporate financial performance relationship: A critical review. Journal of Business Ethics, 145(2), 383-416. https://doi.org/10.1007/s10551-015-2852-5

Groening, C., \& Zhu, Q. (2019). Consumers' role in the green supply chain Handbook on the Sustainable Supply Chain: Edward Elgar Publishing. https://doi.org/10.4337/9781786434272.00015

Hair, Hult, G. T. M., Ringle, C. M., \& Thiele, K. O. (2017). Mirror, mirror on the wall: a comparative evaluation of composite-based structural equation modeling methods. Journal of the Academy of Marketing Science, 45(5), 616-632. https://doi.org/10.1007/s11747-017-0517-x

Hair, Sarstedt, M., Hopkins, L., \& Kuppelwieser, V. (2014). Partial least squares structural equation modeling (PLS-SEM) An emerging tool in business research. European Business Review, 26(2), 106-121. https://doi.org/10.1108/ebr-10-2013-0128

Hedman, J., \& Henningsson, S. (2016). Developing ecological sustainability: a green IS response model. Information Systems Journal, 26(3), 259-287. https://doi.org/10.1111/isj.12095

Henseler, J., Ringle, C. M., \& Sarstedt, M. (2015). A new criterion for assessing discriminant validity in variance-based structural equation modeling. Journal of the Academy of Marketing Science, 43(1), 115-135. https://doi.org/10.1007/s11747-014-0403-8

Higón, D. A., Gholami, R., \& Shirazi, F. (2017). ICT and environmental sustainability: A global perspective. Telematics and Informatics, 34(4), 85-95. https://doi.org/10.1016/j.tele.2017.01.001

Jermsittiparsert, K., Siriattakul, P., \& Sangperm, N. (2019). Predictors of Environmental Performance: Mediating Role of Green Supply Chain Management Practices. International Journal of Supply Chain Management, 8(3), 877-888.

Jermsittiparsert, K., Siriattakul, P., \& Wattanapongphasuk, S. (2019). Determining the Environmental Performance of Indonesian SMEs Influence by Green Supply Chain Practices with Moderating Role of Green HR Practices. International Journal of Supply Chain Management, 8(3), 59-70. https://doi.org/10.1115/1.860281_ch4

Jermsittiparsert, K., Sutduean, J., \& Sutduean, C. (2019). The Mediating Role of Innovation Performance between the Relationship of Green Supply Chain Management Skills and Environmental Performance. International Journal of Supply Chain Management, 8(3), 107-119. https://doi.org/10.7232/iems.2019.18.3.407

Jones, E. L. (2016). Cultures merging: A historical and economic critique of culture (Vol. 26): Princeton University Press.

Kay, R., \& Alder, J. (2017). Coastal planning and management: CRC Press. 
Kim, J., \& Lu, Y. (2019). Information Communication Technology and Global Logistic Performance.

Korkut Altuna, O., \& Arslan, F. M. (2016). Impact Of The Number Of Scale Points On Data Characteristics And Respondents'evaluations: An Experimental Design Approach Using 5-Point'and 7-Point LikertType Scales. Journal of Faculty of Political Science(55). https://doi.org/10.17124/iusiyasal.320009

Karle Pravin P, Dhawale Shashikant C. (2019), "Manilkara zapota (L.) Royen Fruit Peel: A Phytochemical and Pharmacological Review." Systematic Reviews in Pharmacy 10.1, 11-14. https://doi.org/10.5530/srp.2019.1.2

Lucangioli.S. (2018)."Acute Renal Failure: An Article Critique." International Journal of Pharmacy Research \& Technology 8.2, 51-52. https://doi.org/10.31838/ijprt/08.02.07

Lonial, S. C., \& Carter, R. E. (2015). The impact of organizational orientations on medium and small firm performance: A resource-based perspective. Journal of Small Business Management, 53(1), 94-113. https://doi.org/10.1111/jsbm.12054

Lu, C.-C., \& Hsu, H.-J. (2018). Exploring the Relationship between Organizational Capital and Service Innovation Behavior. International Journal of Innovation Education and Research, 6(12), 01-10. https://doi.org/10.31686/ijier.vol6.iss12.1226

Mao, H., Zhang, J., \& Deng, Z. (2016). Information technology resource, knowledge management capability, and competitive advantage: The moderating role of resource commitment. International Journal of Information Management, 36(6), 1062-1074. https://doi.org/10.1016/i.jijnfomgt.2016.07.001

Nan, N., \& Tanriverdi, H. (2017). Unifying the Role of IT in Hyperturbulence and Competitive Advantage Via a Multilevel Perspective of IS Strategy. Mis Quarterly, 41(3), 937-958. https://doi.org/10.25300/misq/2017/41.3.12

Nejati, M., Mohamed, B., \& Omar, S. I. (2015). The Influence of Perceived Environmental Impacts of Tourism on the Perceived Importance of Sustainable Tourism. E-review of Tourism Research, 12.

Nesselroade, K. P., \& Grimm, L. G. (2019). Statistical Applications for the Behavioral and Social Sciences: Wiley Online Library.

Nguyen, A., \& Nguyen, T. (2018). Free cash flow and corporate profitability in emerging economies: Empirical evidence from Vietnam. Economics Bulletin, 38(1), 211-220.

Qiu, Y., Shaukat, A., \& Tharyan, R. (2016). Environmental and social disclosures: Link with corporate financial performance. The British Accounting Review, 48(1), 102-116. https://doi.org/10.1016/j.bar.2014.10.007

Radu, L.-D. (2017). Green Information System for a Sustainable Enterprise Sustainable Entrepreneurship and Investments in the Green Economy (pp. 144-168): IGI Global. https://doi.org/10.4018/978-1-5225-2075-7.ch005

Somjai, S. \& Jermsittiparsert, K. (2019). The Trade-off between Cost and Environmental Performance in the Presence of Sustainable Supply Chain. International Journal of Supply Chain Management, 8(4), 237-247.

Taheri, A., \& Stevenson, R. (2017). Environmental Compliance and US Industrial Productivity Growth.

Tang, C. M., \& Chaw, L. Y. (2016). Digital Literacy: A Prerequisite for Effective Learning in a Blended Learning Environment? Electronic Journal of E-learning, 14(1), 54-65.

Vracheva, V., Judge, W. Q., \& Madden, T. (2016). Enterprise strategy concept, measurement, and validation: Integrating stakeholder engagement into the firm's strategic architecture. European Management Journal, 34(4), 374-385. https://doi.org/10.1016/j.emj.2015.12.005

Yagi, A. (2015). Putative prophylaxes of Aloe vera for age-related diseases. Journal of Gastroenterology and Hepatology Research, 4(1), 1407-1424. https://doi.org/10.17554/j.issn.2224-3992.2015.04.416 
